\title{
COMPARISON OF REGIONAL STRUCTURES OF PRODUCTION: A STUDY IN DEVELOPMENT STRATEGY
}

\author{
Suresh Deman*
}

\section{Section I}

Input-output techniques have acquired a pivotal place in the conversion specifications of objective functions and in the planning of structural relations of an economy. The synoptic intent of this work is to review various operational applications of regional intersectoral patterns of linkages and complementarities that may be useful in formulating an appropriate strategy for regional economic development. Input-output techniques are extensively used for this purpose.

There does not exist any fool proof strategy for formulating regional development strategy. One view is that the "leading sectors" are identified on the basis of interindustry linkages and essential resources as production proceeds in the use of inputs. This assumes a reasonable expectation that the relevant output can be sold within these sectors. The other view studies structural changes in the process of economic growth on the basis of linkages. This can be accomplished by comparing the scale as well as the ranking of sectors between groups of regions based on interindustry linkages. On this basis one could test Hirschman's unbalanced growth hypothesis that high priority be given to the sectors which have high linkages and low priority to others. However, Yutopoulos and Nugent's (1973) studies do not find much support in favor of Hirschman's perspective.

There is an alternative hypothesis which regards regional development as the change induced by natural resource oriented and export-base industries. Such industries are located on the basis of transport, technological and resource cost advantages of a specific region over the

\footnotetext{
'Research Fellow, Australian National University. This paper is an extensions of my M. Phil. thesis work under the direction of Professor Amitabh Kundu, Jawahar Lal Nehru University, New Delhi, which was completed at the University of Pittsburgh. I have greatly benefited from the many comments and suggestions of Professors C.R. Rao, Hirotada Kohno, Lance Taylor, K.P. Kalirajan, Subhash Ray, Andrew Isserman, Gene Gruver, Reuben Slesinger, Asatoshi Maeshiro, and from earlier studies by Dr. G.S. Bhalla and Y.K. Alagh. The anonymous referees comments were very useful. Lastly, but not the least, goes my appreciation to my wife, Ms. Jennifer L. Mayo-Deman, for typing the manuscript and Sushila Deman for computation.
}

others. Therefore, identifying regional trade flows for studying cost disadvantages of natural resource oriented industries is very important. Similarly, changes in demand outside the region, natural resource position, changes in technology and relative costs of factor inputs, etc., should be tackled directly for evolving any regional development strategy rather than basing decisions on the size and pattem of linkages.

\section{Section II}

A number of input-output studies of single regions have been undertaken in order to assess the impact on the economy: Chapman and Shellhammer (1967), Emerson (1969), Bourque and Weeks (1969), and Miernyk (1970) for example. Simultaneously, attempts were made in India to construct regional input-output tables for various regions, e.g., Kotiand Santhanam (1963), Ragnekar(1969), Kashyap and Alagh (1971), Ghosh (1974), Bhalla (1975), and Mehta (1977). Partial input-output models from All India Survey of Industries data were also constructed for various other regions.

Such ex post facto input-output tables, without any regional and sectoral disaggregation, give many insights into the structure of the economy. In general, the density of an input-output table indicates the relative degree of interdependence of various sectors and provides an instructive index of industrial diversification and development as it relates to the number and intensity of forward and backward linkages. On the other hand, the many blank entries of these tables indicate the relative underdevelopment of an economy.

In general, the historical utilization of input-output techniques can be divided into three broad applications: a) local input-output studies; b) regional balance-of-payments studies; and c) interregional flow studies. The input-output models briefly referred to above are open with respect to the final demand vector, but may be closed. The household consumption demand can be endogenously determined by national income, which itself is determined by the intersectoral linkages in the economy.

The input-output structure may be readily adapted for the study of regional differences in the structure of production. In fact, detailed structural relations may be exploited to a high degree for the purpose of pinpointing 
regional characteristics in many areas, including development, an area that has much relevance for this study.

The structural relations of an economic system represented by the matrix of input-output coefficients traditionally has been reflected in estimates of the linkage relationship among different sectors of the economy. The degree of responsiveness of the system would depend on the nature of the interdependencies that exist to the extent the system of sectoral classifications depict integrated or decomposable patterns, which in turn depend upon the pattern of linkages, concepts and types.

The classification of linkages - backward and forward - accords with the study of sectoral interdependencies on both the demand and the supply sides. However, there is no necessary connection between the two measures for any single sector.

The relative importance of these linkages depends on the nature of the economy. For an economy which is not sufficiently developed, especially one which is beginning capital development, forward linkages are very important. Evaluations of linkages in such cases entail an extended analysis of existing resources, of those conditions which must first be created in order to expand industrial construction, i.e., backward linkages, and of those consequences brought about by implementing the decisions taken, i.e., forward linkages. Usually backward linkages stimulate the establishment of a chain of auxiliary industries bringing into existence additional capacity and economic resources, which may be viewed as being very important for an industrially developed economy.

Comparison of the production structures of different economies has largely focused on international comparisons: Chenery and Watanabe (1958), Simpson and Tsukui (1965), Leontief (1967), Helmstadter (1969), Long (1970), and Santhanam and Patil (1972). Regional comparisons of production structures, however, become possible subsequent to the development in recent years of several survey and non-survey type input-output techniques. Such an attempt was made by Emerson (1971). The task of regional structures is easier because of the variation in accounting conventions, relative prices, etc., is smaller in contrast to international structures of production, comparisons of which sometimes involve two qualitatively different economic systems.

Rasmussen (1956) suggested a refined way of computing linkages. He makes use of the inverse of the input coefficient matrix for this purpose and defines the "index of power of dispersion" and the "index of sensitivity of dispersion." These indices show something somewhat analogous to a backward linkage effect.

A path-breaking analysis of input-output tables of different countries by Chenery and Watanabe (1958) con- cluded that despite substantial differences in individual input-output coefficients, there exists a general similarity in the relationships among productive sectors of the economies in industrialized countries. They examined interdependencies in the production structure from both the demand and the supply side. Frequently, strong linkages are observed when the production sector draws heavily from other sectors or produces mostly for intermediate use.

Simpson and Tsukui (1965) described the above studies as merely taxonomic and suggested that there are certain fundamental elements (purely technical in character) which may be found in the productive structure of modern economies irrespective of the nature of their economic systems and dissimilar production coefficients. These distinctive characteristics are: decomposability, bloc independence, triangularity, and physical homogeneity of blocs. They grouped sectors according to their physical qualities; blocs were arranged as a metal bloc, a non-metal bloc, an energy bloc, and a service bloc in a triangular way.

Mennes-Tinbergen and Waardenburge (1969) further emphasized that these sectors are not only bloc triangular, but bloc diagonal, provided the service sector is excluded. This means that no sector of a particular bloc is related to a sector in another bloc.

Long, Jr., (1970) suggested two procedures for comparing the structures of production of different types of economies on the basis of different goods, resource endowments, degree of efficiency and of different stages of economic development. The first investigates the sectoral representation of the structure of gross output broken down in percentages of the total. The second procedure investigates each sector by using an extension of a set of concepts introduced by Chenery and Watanabe. Dissimilarities reflected in the difference in gross output and shares appear more frequently in group classifications.

Emerson (1971) compared interindustry regionalnational economic structures of similar size and level of development and extended the analysis suggested in previous studies to include the study of the internal economic structure as well as the technical structures of economies. $\mathrm{He}$ also presented a supportive quantitative analysis by examining the internal effects.

Santhanam and Patil (1972) suggested another measure of interdependence termed the "Interdependence Ratio". They found this ratio very useful in classifying industries into several categories according to various features of distinctiveness. Furthermore, their study provided additional evidence supporting the main finding of the pioneering study of Chenery and Watanabe (1958) that similarities exist in the production structure and in the pattern of intermediate use of commodities as well as in input coefficients. 
Yutopoulos and Nugent (1973) formulated the linkage hypothesis on the basis of the total linkage index $\mathrm{L}_{\mathrm{Tj}}$. They claimed superiority of the total linkage index over the classical tetrapartite classification suggested by CheneryWatanabe-Hirschman. The following reasons were given to support their measure of linkages: i) "it includes indirect as well as direct backward linkages; ii) it combines with forward linkage effects; and iii) it permits cardinal as opposed to only ordinal measurement." The finding of Hirschman's unbalanced-growth theory cannot be substantiated on the basis of empirical data. However, the balanced-growth version of the linkage hypothesis is generally supported. The linkages are important but only as indicators of the optimum degree of deviations that should be allowed between sectoral and overall rates of growth. This view generated a debate in the development literature. A series of scholarly articles appeared challenging the above measure of linkages and the linkage hypothesis.

Laumas (1976) questioned the superiority of the total linkage index by using the inverse of Leontief's inputoutput matrix. He suggested a weighted $\mathrm{L}_{T_{j}}$ according to a given sector's share in the final demand to demonstrate the demand approach to economic development proposed by Hirschman.

Boucher (1976) challenged the second and the third reasons above used in support of the total linkage index. He showed that $\mathrm{L}_{\mathrm{T} j}$ neither includes nor combines with forward linkage effects.

A note by Riedel (1976) suggests that Yutopoulos and Nugent's test of the Hirschman linkage hypothesis is invalid. He claimed that the LTj shows the actual existing linkages in the economy if and only if all intermediate inputs are produced and supplied domestically. In developing countries, a significant proportion of intermediate inputs are imported; hence, $\mathrm{L}_{\mathrm{Tj}}=\Sigma_{\mathrm{i}} \mathrm{a}_{\mathrm{ij}}{ }_{\mathrm{ij}}$ will be quite erroneous measure of existing linkages. Besides the weakness of the linkage hypothesis, one can also question the presumption that linkage provides a kind of deux ex machina by which entrepreneurial abilities and decision-making are generated. Evidence from the experiences of developing countries suggests otherwise.

While eulogizing the merits of the linkage hypothesis, Jones (1976) concluded that "whatever the merits of their test structure, the Yutopoulos and Nugent measurement of linkages share three failings of all previous works, namely: a) misspecification of direct and indirect linkages; b) confusion between 'domestic' and 'world linkages'; and c) excessive aggregation."

He proposed a solution to the first two problems and suggested the danger of aggregation using Korean data.

In a concluding article Yutopoulos and Nugent(1976) defended their linkage hypothesis after using all the indices suggested by their critics. They claim that even if they had opted for one of the suggested alternative indices, the conclusion would not likely have been invariant.

They further studied the sectoral linkage indices and established a more generally significant similarity in the structural relations among developed and developing countries. They used total linkage indicators of different sectors between the two groups of countries, and found that the structure of linkages is in general higher in the developed than in the developing countries. Further, they applied the Chenery, Watanabe, Hirschman tetra-partial classification and similarly ranked sectors according to the ordering revealed between different types of countries.

Jones (1976) pointed out that the similarities in the structure of production, however, are the result of the unsatisfactory treatment of trade flows in which imported and domestic intermediates are grouped together. Consequently, "world linkages" are identified rather than domestic linkages. The former usually are very similar, though the latter are not, owing to differences in trade flows described in regional-national input-output tables. Therefore, "when measuring potential long-run linkages ex ante, one should utilize a flow matrix incorporating producibles within the time frame being analyzed. On the other hand, if one is using an end of period table to measure linkages ex post facto, then only the domestic flows are relevant, since induced import substitution will have already taken place."

Schultz (1977) has suggested a scheme of weighting the backward linkages by share of sector regarding intermediate input, and the forward linkages by the share of sector in intermediate output.

Structural studies focusing on international comparisons have shown that a fundamental structure of production is shared by developed countries. However, a regional economy has less structural interdependence and a more pronounced bloc triangularity than a national economy, if we compare internal structures. The explanation is that the regional-import coefficients are higher than the national import coefficients because of the inclusion of imports from other regions, in addition to imports from abroad. Thus, the expectation is formed that the internal structure of regional economies appropriately reflect specialization and pronounced triangularity characteristics.

\section{Section III}

The Planning Commission in India employs inputoutput models for formulating development plans. Widely disaggregated input-output tables constructed by Saluja (1961), Mathur (1969), and Rudra (1975) were used for this purpose. However, most states in India do not have 
regional input-output tables prepared and even if they do, these input-output tables are seldomly used. Kashyap and Alagh (1971) were the first to make use of input-output tables at the regional level in fixing priorities for resources allocation and in formulating a perspective plan for the state of Gujarat.

The sectoral interdependence and the comparison of structures of production have been studied empirically for the purpose of formulating a suitable regional development strategy for two contrasting regions in India. The heart of the study iscomposed of input-output tables for the regions of Haryana and Gujarat. The first region is agriculturally developed and the latter is an industrialized region of India. These regions also have certain common features relating to the shares of the primary sectors in generating output and income within the primary sectors and between the primary sectors and the secondary sectors. There are also similar pattems in variations of productivity per worker among the economic activities. However, the share of the primary sectors and the average productivity per worker for Gujarat were lower than for Haryana. On the other hand, compared to Haryana the productivity differences in Gujarat between the farm sectors and industrial activities in terms of generating income and output were substantial. Relatively, underdeveloped agriculture and more advanced industrialization of the Gujarat economy may have resulted in such a contrasting pattern.

The Haryana economy as compared to Gujarat shows a trade surplus which was further exaggerated because of the exclusion of trade margins from the structural inputoutput matrix. However, this is consistent with the comparative advantages that the Haryana economy has come to realize in agriculture production with the event of the "Green Revolution." Rural per capita consumption for Gujarat is seen to be higher than in urban areas which reflects the relative well being of the rural population as compared to India in general and Gujarat in particular. A study by Vyas (1975) confirms that a growing segment of the rural population of Gujarat has added to the rank of small farmers and landless laborers who are facing increasing impoverishment. Such an observed pattern of consumption seems to support the hypothesis:

\section{“...per capita consumption of food does not depend upon per capita income alone; that is, it is higher, higher the per capita output of food grains within each state, and lower the greater the inequality in the distribution of land holdings."}

There are several other regional input-output tables which have not been considered for comparison because of serious limitations in their construction. However, before such an analysis can be carried out, two types of adjustments, the nontechnical and the technical must be made. The nontechnical adjustments concern differences in relative prices, level of income and accounting conventions. The technical adjustments concern the aggregation of sectors and the size of the input- output tables.

The method of double inversion was suggested by Leontief (1967) as an alternative to aggregation in inputoutputanalysis and national accounts. This method reduces the dimension of input-output tables without distortion of any of the basic structural relationships of production. However, he realizes the limitation of this method for comparing the structures of production which are described only in terms of input-output relationships between goods and services of directly comparable kinds. The present paper does not attempt Leontief's type of aggregation since most of the characteristics of the regional structuresare retained even after theaggregation. Furthermore, I have also computed linkages by using other methods without aggregating the input-output tables. Most of the conclusions are invariant; hence, important dissimilarities between regional production structures are not destroyed in the process of aggregation.

The input-output tables of the above regions are dissimilar with regard to their sectoral classification. For example, the Haryana input-output table has been disaggregated to 32 sectors including eight agriculture sectors. Gujarat's table is comprised of 16 sectors with only one devoted to agriculture.

In order to facilitate a comparison, the tables must be both of the same dimension and sectoral classification. Therefore, the sectors are consolidated into twelve rows, through aggregation, a number which is adequate for the purposes of comparison as well as for reducing computational work.

Four basic criteria were used to arrive at the common dimension. First, sectors were aggregated to the extent that they share a relatively homogeneous input-output structure. The second consideration relates to the relative importance of a sector in terms of its contribution to total regional output. As a third criterion, the sectoral classification, was set up on the basis of a maximum similarity between the flows' tables. Finally, an attempthas been made to construct the sectors in such a manner that they follow a pattern that would facilitate the task of comparing the two economies. A detailed description of the scheme of sectoral classification and aggregation is given in Table 1.

However, the feasibility of this type of comparison of regional economies depends largely on the extent to which the original data are comparable. Most of the ad hoc decisions in this study are taken in the process of computing the input tables; notall of them are recorded in the supporting 
Table 1

Sectoral Aggregation \& Inequality Coefficients by Sector

\begin{tabular}{|c|c|c|c|c|}
\hline Sectors & Regions & $\frac{\text { Gujarat }}{1}$ & $\frac{\text { Haryana }}{2}$ & $\begin{array}{l}\text { Inequality Coef. } \\
\text { Haryana \& Gujarat }\end{array}$ \\
\hline 1. Agriculture and allied & & 1 & $1-8,10,11$ & 0.466 \\
\hline 2. Agro-based Industries & & $2,3,4$ & $12,13,14$ & 0.571 \\
\hline 3. Textiles & & 6 & 15,16 & 0.455 \\
\hline \multicolumn{5}{|l|}{ 4. Chemical and Petroleum } \\
\hline Products & & $5,7,16$ & 21 & 1.198 \\
\hline 5. Mining & & 13 & & 2.000 \\
\hline \multicolumn{5}{|l|}{ 6. Basic Metal and Metal } \\
\hline Products & & 9 & 23,24 & 1.400 \\
\hline \multicolumn{5}{|l|}{ 7. Non-metallic Mineral } \\
\hline Products & & 8 & 22 & 0.656 \\
\hline 8. Equipment & & 10 & $25-30$ & 0.475 \\
\hline \multicolumn{5}{|l|}{ 9. Wood, Paper, Leather } \\
\hline and Rubber & & 11 & $17-20$ & 0.595 \\
\hline 10. Miscellaneous Products & & 12 & 31 & 0.755 \\
\hline 11. Construction & & 14 & 9 & 0.908 \\
\hline \multicolumn{5}{|l|}{ 12. Electricity, Power } \\
\hline and Water & & 15 & 32 & 0.975 \\
\hline Average Inequality Coefficient & & & & 0.871 \\
\hline
\end{tabular}

Source: The dimension of the Gujarat I-O table is (24X24). There are twenty-one organized industrial sectors and three non-industrial sectors. The Haryana I-O table is (32X32), of these, twenty-one belong to organized industries, eight to agriculture and allied activities, and one each pertaining to electricity and construction. There is no mining sector in the Haryana economy. These tables have been aggregated to a common dimension of (12X12).

documentations; and the degree of comparability must be determined to some extent through internal checks in the course of analysis. These are necessary qualifications of the study's results and analysis.

The regional differences that exist in the Leontief coefficients of these tables, to the extent that they are not random, may reflect differences in resource endowments, levels of income, size of regions, regional institutions and presumably tastesreflected in the structure of final demand. Very importantly, the success of input-output analysis in an attempt to identify structural differences among regions largely depends on the techniques used for the construction of these tables.

The extent of similarity between input-output coefficients can be determined by Mennes (1969) inequality coefficient which is given by:

$$
P_{j}^{r s}=\frac{\Sigma a_{i j}^{r}+a_{i j}^{s}}{1 / 2 \Sigma\left(a_{i j}^{r}+a_{i j}^{s}\right)}
$$

Where: $r, s$ refer to two different regions respectively; aij = input-output coefficient.

The linkages and the "index of power of dispersion" as suggested by Rasmussen can be calculated as follows:

$$
U_{\cdot j}=\frac{1 / n Z_{\cdot j}}{1 / n^{2} \sum_{j=1}^{n} Z_{\cdot j}} \quad(j=1,2,3, \ldots, n)
$$

Where $\mathrm{Z}_{\mathrm{j}}=\Sigma_{\mathrm{i}} \mathrm{Z}_{\mathrm{ij}}$ and $\mathrm{Z}_{\mathrm{ij}}$ is the appropriate element in the inverse matrix.

$U_{j}$ measures the relative extent to which an increase in final demand for the product of industry $\mathrm{j}$ is dispersed throughout the system of industries. Analogous to the forward linkage effect, he defines the "index of sensitivity of dispersion" given by:

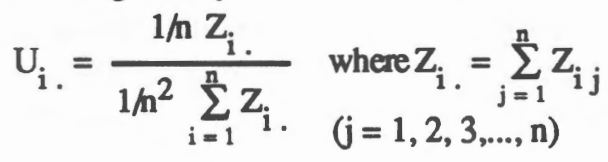


$U_{i}$ measures the extent to which the system of industries draws upon the jth industry. The indices can also be interpreted as a measure of Hirschman's backward and forward linkages, which measure the effects of increased output in one sector relative to those of all sectors. If $U$ is less than 1.0, the sector in question produces only weak output stimuli for the economy. A value greater than 1.0, however, would signal that this sector is transmitting above-average impulses to others via its intermediate input requirements.

In order to overcome the difficulty of the method of averaging in measuring the "index of dispersion" and "index of sensitivity of dispersion", a measure of variability was introduced which may be defined as:

$$
v_{j}=\frac{1 / n-1 \sum_{i=1}^{n}\left(z_{i j}-1 / n \sum_{i=1}^{n} z_{1 j}\right)^{2}}{1 / n \sum_{i=1}^{n} z_{i j}}(j=1,2, \ldots, n)
$$

and

$$
v_{i}=\frac{1 / n-1 \sum_{j=1}^{n}\left(z_{i j}-1 / n \sum_{j=1}^{n} z_{i j}\right)^{2}}{1 / n \sum_{j=1}^{n} z_{i j}}(i=1,2, \ldots, n)
$$

If $V_{j}$ is high then it would mean that a particular sector draws heavily on one or a few sectors and a low value for $V_{j}$ would mean that an industry draws evenly from the other sectors.

A sector with high $\mathrm{V}_{\mathrm{j}}$ and $\mathrm{U}_{\mathrm{j}}$, if accompanied by a low value for indices of the coefficient of variation, is characterized as "the key sector." Hirschman's definition of "the key sector" does not put any restriction on variability characteristics and he thus disregarded the "spread effects" on the development of an industry.

The linkage techniques have been further extended to capture the income and employment effects. The output multiplier matrix are weighted by income or employment coefficient to derive the relevant matrices for the purposes of studying other objectives of regional development like the employment and income generation.

Consider the system of equations of the basic model: $\mathrm{Z}_{\mathrm{ij}}=(\mathrm{I}-\mathrm{A})^{-1} ; \mathrm{W}=\langle\mathrm{L}\rangle(\mathrm{I}-\mathrm{A})^{-1} ; \mathrm{Y}=\langle\mathrm{V}\rangle(\mathrm{I}-\mathrm{A})^{-1}$;$$
\mathbf{N}=\langle\mathrm{L}\rangle(\mathrm{i}-\mathrm{A})^{-1} ; \mathbf{N}^{\prime}=\left\langle\mathrm{L}^{\prime}\right\rangle(\mathrm{I}-\mathrm{A})^{-1}
$$

Where $Z_{i j}, W, Y$, and $N$ represent the output wage, income and man-hours multiplier matrices, and $\langle\mathrm{L}\rangle,\langle\mathrm{V}\rangle,\langle\mathrm{N}\rangle$, and $\langle L$ ' $\rangle$ are defined as the diagonal matrices for the sectoral wage-output ratio, value added-output ratio, manhours-output ratio and the labor employment multiplier matrix, respectively.
The above measures of linkages do not account for import leakages. It is worth mentioning here that the actual linkages realized by a group of industries would differ from potential linkages where leakages due to competitive imports are taken into account. A simple technique is used for computing import leakages. Bhalla (1976) defines:

$$
\mathrm{R}=(\mathrm{I}+\langle\mathrm{M}\rangle-\mathrm{A})^{-1}
$$

where $\langle\mathrm{M}\rangle$ is a diagonal matrix of import coefficients $M$ Given R, we can calculate W, Y,N, and N' matrices which would give new multipliers after allowing for import leakages.

The input-output linkages relationship as defined by Chenery and Watanabe (1958) are computed as follows:

$$
\begin{aligned}
& L_{B j}=\frac{\sum_{i=1}^{n} x_{i j}}{x_{j}}=\sum_{i=1}^{n} a_{i j}=\frac{u_{j}}{x_{j}} \\
& L_{F i}=\frac{\sum_{j=1}^{n} x_{i j}}{z_{i}}=\frac{w_{i}}{z_{i}}
\end{aligned}
$$

where: $L_{B j}$ and $L_{R}$ are unweighted backward and forward linkages respectively.

$X_{i j}=$ number of units of commodity $i$ used in production $x j$. $\mathrm{Z}_{\mathrm{i}}=$ the total demand which is the sum of the interindustry demand and the final demand for commodity $i$, given by:

$$
\begin{aligned}
& Z_{i}=\sum_{j=1}^{n} X_{i j}+Y_{i}=W_{i}+Y_{i} \\
& U_{j}=\sum_{i=1}^{n} X_{i j} \text { and } W_{i}=\sum_{j=1}^{n} X_{i j}
\end{aligned}
$$

The above mentioned concept of linkages can be modified according to Siegfried Schultz (1977) by attaching appropriate weights to the linkage ratios, provided that the backward and forward linkages denoted by $\mathrm{U}_{B}$ and $\mathrm{W}_{B}$, are weighted by share of sector in intermediate inputs and outputs, respectively. Altematively, when weighted by the share of the gross output of the overall economy, the backward and forward linkages are denoted by $\mathrm{U}_{c}$ and $\mathrm{W}_{\mathrm{c}}$.

The total linkage multiplier, $\mathrm{L}_{\mathrm{rj}}$ as suggested by Yutopoulos and Nugent (1976), can be computed as follows:

$$
\mathrm{L}_{\mathrm{T} j}=\sum_{\mathrm{j}=1}^{\mathrm{n}} \mathrm{a}_{\mathrm{ij}}^{*} \text { where } \mathrm{a}_{\mathrm{ij}}^{*}=\left(\mathrm{I}-\mathrm{a}_{\mathrm{ij}}\right)^{-1}
$$

This total linkage index gives a unique cardinal ordering of sectors and captures not only the first round backward and forward interactions among industries but also the additional increase in output induced in subsequent rounds. 
The problem of identifying regional trade flows in the absence of trade data was tackled in two more commonly used alternatives. The first alternative was suggested by Dutta-Choudhari (1975). He assumed fixed technology coefficients from an input-output table and introduced an interregional trade-flow matrix in fixed proportions of the following form:

subject: $\sum_{j}^{s}{ }_{j}^{\alpha \beta}=1$ for all $j=1,2, \ldots$, nand $\beta=1,2, \ldots, s=1 \alpha=1$ and there are $s$ regions in the economy.

where: $\mathbf{X}_{\mathrm{j}}=$ is the production of commodity $\mathbf{j}$

$\mathrm{Z}_{\mathrm{j}}=$ is the total requirement of commodity $\mathrm{j}$;

$t_{j}=$ is the proportion of the $\alpha$ of the region's total requirement of the jth commodity met out of the production of the $\beta$ th region

In the second alternative, a technology matrix is identified independently that gives us not only the total intermediate demand but a regional consumption and investment vector as well as private and government consumption plus investment. The two together establish the total requirement. Net export, as a residual, can be calculated by subtracting total production from the above. The advantage of this approach is that it is possible to adjust noncompetitive import figures on intermediate products by introducing a row vector for such imports in the inputoutput system. Morawski(1973) suggested this possibility of generating an interregional trade-flow matrix, at least on a net export or import basis, provided regional input-output tables are available for all regions.

\section{Section IV}

In this section the input-output tables of Haryana and Gujarat are compared in the context of the discussion set forth in the earlier sections. More specifically, the regional structural differences attributable to differences in natural endowments, technologies and final demand compositions are discussed.

The empirical investigations relating to the various types of linkages by one of the techniques discussed in Section III have been undertaken in order to arrive at conclusions with respect to structural changes in the process of growth and for evolving a suitable strategy for regional development. This is achieved by comparing the scale as well as the ordering of sectors according to linkages between groups of regions and by the identifications of key sectors.

The proportion of different sectors to total regional output reflects alternative levels of natural endowment on the one hand, and the level of development on the other. Different shares in economic activity were found which reflect both unequal levels of natural endowments and unequal patterns in levels of economic development.

The sectoral composition of state domestic production or net value added is the conventional measure reflecting the stage of development in the economy. From this point of view, Gujarat is more developed because agriculture, animal husbandry and the agro-based industrial sector (excluding textile) accounts for 68 percent in Gujarat as against 78 percent in Haryana.

Inequality coefficients are shown in Table 1 to determine the extent of similarity in the input-output coefficients. The smaller the ratios, the more similar is the structure of production in the two regions. If the structures are completely uncorrelated, then the inequality coefficient will be 2.0. In our study, the comparison of the two region's input-output tables has been performed on a more aggregative basis. However, the conclusions that emerge confirm the Mennes-Tinbergen and Waardenburge findings. That is, to say, the sectors producing commodities that are relatively more mobile among countries have lower inequality coefficients than the more resource-based sectors such as agriculture, forestry andmining. Similarly, services that must be provided locally, e.g., transport, trade, electricity and services also have higher inequality coefficients. On this basis, the agriculture and agriculturally related sectors are quite dissimilar, and the manufacturing sectors are more similar for Haryana and Gujarat.

\section{General Linkage Pattern}

We have computed linkage indices both with and without import leakages for the disaggregated input-output tables of Gujarat and Haryana. Measures of forward and backward linkages for two regions are shown in Tables 2 , 3,4 , and 5 . Both of these ratios are indicators of sectoral interdependence and thus may serve as criteria for distinguishing sectors according to the intensity of their linkage with the rest of the economy. In order to incorporate the size of a sector's transactions, the linkage measures have been weighted by the share of the sectoral gross output to gross output of the entire economy.

The overall linkage indices are quite contrasting and do not follow any set patterns according to development hypotheses. The backward or forward linkages calculated on the basis of output, employment, income and wage income multiplier matrices rarely indicate high values for any sector. These patterns of linkages are not distorted significantly when import leakages are accounted for. In the context of linkage analysis as mentioned above, the 
Table 2

Rank Correlation of Linkages for Gujarat and Haryana (1969-70), with Import Leakages

Gujarat

Linkage Indices on Matrix Multipliers

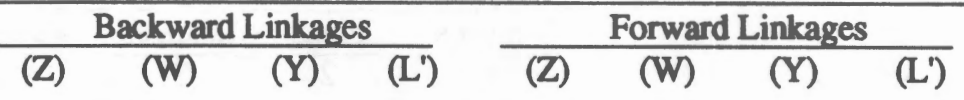

1. Input inducement

2. Wage income inducement

3. Income Inducement

$\begin{array}{llllll}\text { (Z) } & 1.0 & - & - & - & 1.0 \\ \text { (W) } & 0.13 & 1.0 & - & - & 0.34\end{array}$

$(1)$

$\begin{array}{llllll}\text { (Y) } & 0.15 & 0.67 & 1.0 & - & 0.48\end{array}$

4. Employment Inducement

$\begin{array}{llll}\text { (L') } \quad 0.03 & 0.61 & 0.83 & 1.0\end{array}$

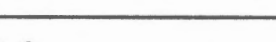

(L)

Haryana

Linkage Indices based on Matrix Multipliers Measuring Inducement

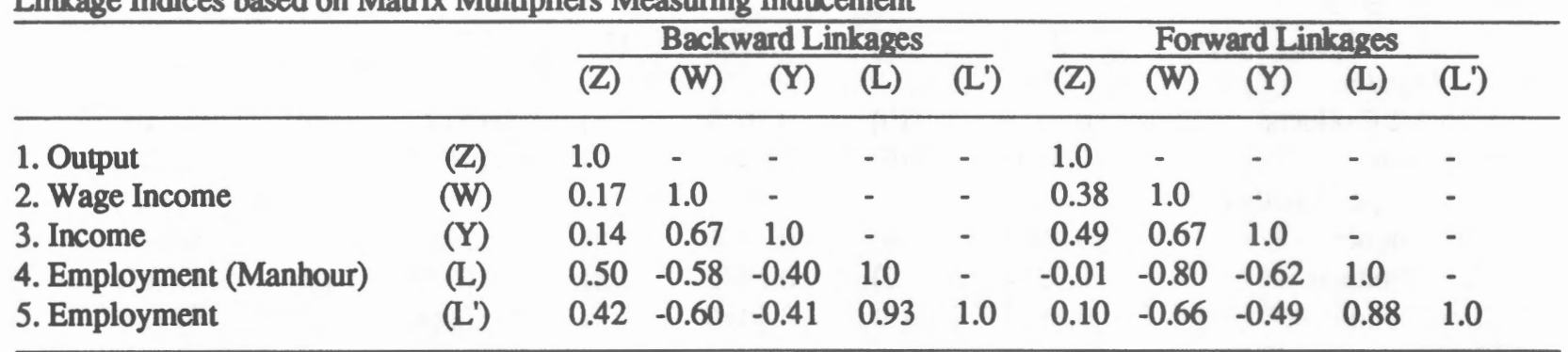

Source: Rank correlations are derived from various backward and forward linkage indices along with their ranks computed from inputoutput tables of Gujarat and Haryana with import leakages.

Rank Correlation of Linkage for Gujarat and Haryana (1969-70), without Import Leakages

Gujarat

Linkage Indices on Matrix Multipliers

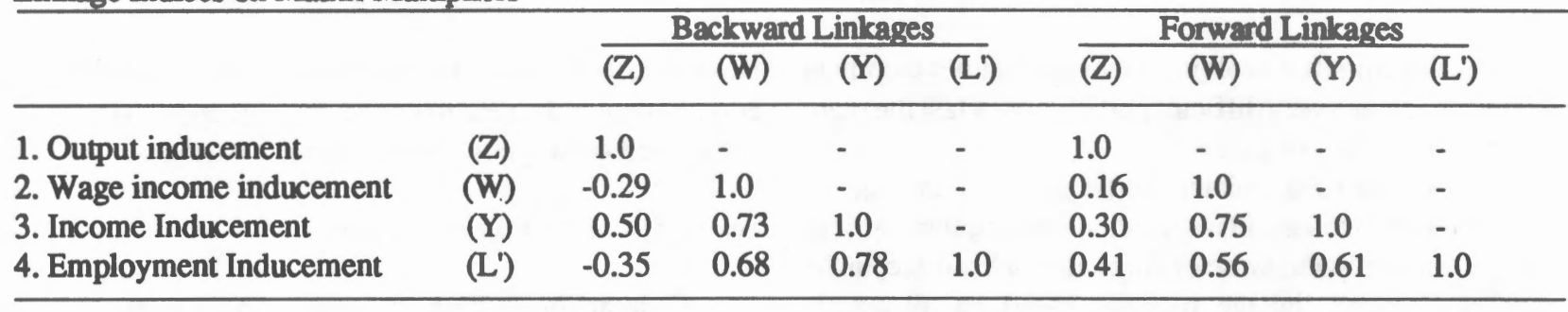

Haryana

Linkage Indices based on Matrix Multipliers Measuring Inducement

\begin{tabular}{|c|c|c|c|c|c|c|c|c|c|c|c|}
\hline & & $\overline{(Z)}$ & (W) & $(Y)$ & (L) & $\overline{\left(\mathrm{L}^{\prime}\right)}$ & $\overline{(\mathrm{Z})}$ & (W) & (Y) & (L) & $\overline{\left(L^{\prime}\right.}$ \\
\hline ut Inducement & $(\mathrm{Z})$ & 1.0 & - & - & - & - & 1.0 & - & - & - & \\
\hline Income Inducement & (W) & -0.15 & 1.0 & . & - & - & 0.44 & 1.0 & - & - & - \\
\hline $\begin{array}{l}\text { ne Inducement } \\
\text { oyment Induceme }\end{array}$ & (Y) & -0.21 & 0.59 & 1.0 & - & - & 0.50 & 0.77 & 1.0 & - & \\
\hline & (L & 0.67 & -0.41 & -0.34 & 18 & - & 0.17 & -0.62 & -0.48 & 1.0 & \\
\hline oyment & $\left(L^{\prime}\right)$ & 0.62 & -0.62 & -0.40 & 0.87 & 1.0 & 0.12 & -0.57 & -0.42 & 0.89 & \\
\hline
\end{tabular}

Source: Rank correlations are derived from various backward and forward linkage indices along with their ranks computed from inputoutput tables of Gujarat and Haryana without import leakages. 
Table 3

Backward and Forward Linkages; Unweighted

\begin{tabular}{|c|c|c|c|c|c|c|c|c|}
\hline \multirow[t]{2}{*}{ Linkages, Ranks, Regions } & \multicolumn{2}{|c|}{$\begin{array}{l}\text { Backward }\left(U_{A}\right) \\
\text { Haryana }\end{array}$} & \multicolumn{6}{|c|}{ Forward $\left(\mathrm{W}_{\mathrm{A}}\right)$} \\
\hline & linkages & ranks & linkages & ranks & linkages & ranks & linkages & ranks \\
\hline Sectors & 1 & 2 & 3 & $\overline{4}$ & 5 & 6 & 7 & 8 \\
\hline 1. Agriculture and allied & 0.2264 & (10) & 0.1910 & (9) & 0.3677 & (5) & 0.4101 & (7) \\
\hline 2. Agro-based Industries & 0.6509 & (1) & 0.7498 & (1) & 0.0586 & (9) & 0.2757 & (8) \\
\hline 3. Textiles & 0.5310 & (2) & 0.4962 & (2) & 0.2207 & (6) & 0.2014 & (9) \\
\hline 4. Chemicals and & & & & & & & & \\
\hline Petroleum Products & 0.5152 & (3) & 0.3999 & (4) & 2.9256 & (1) & 0.5465 & (6) \\
\hline 5. Mining & 0.0000 & (12) & 0.0605 & (12) & 0.0000 & (12) & 1.0877 & (1) \\
\hline 6. Basic Metal and & & & & & & & & \\
\hline Metal Products & 0.3241 & (8) & 0.1122 & (11) & 0.7541 & (2) & 0.7270 & (4) \\
\hline 7. Non-Metallic & & & & & & & & \\
\hline Mineral Products & 0.2815 & (9) & 0.3029 & (6) & 0.5177 & (4) & 0.7401 & (3) \\
\hline 8. Equipment & 0.3504 & (6) & 0.2390 & (7) & 0.1015 & (8) & 0.1348 & (10) \\
\hline 9. Wood, Paper, Leather & & & & & & & & \\
\hline and Rubber & 0.4017 & (4) & 0.3576 & (5) & 0.2205 & (7) & 0.6612 & (5) \\
\hline 10. Misc. Products & 0.3274 & (7) & 0.1992 & (8) & 0.0350 & (10) & 0.0374 & (11) \\
\hline 11. Construction & 0.3817 & (5) & 0.4446 & (3) & 0.0000 & (11) & 0.0001 & (12) \\
\hline 12. Electricity, & & & & & & & & \\
\hline Power and Water & 0.0586 & (11) & 0.1705 & (10) & 0.6014 & (3) & 0.8694 & (2) \\
\hline $\begin{array}{l}\text { Average backward and } \\
\text { forward linkages }\end{array}$ & 0.3176 & & 0.3504 & & 0.3176 & & 0.3504 & \\
\hline
\end{tabular}

Source: The unweighted backward and forward linkages are derived from the aggregated input-output table (12X12) of the Gujarat and the Haryana economies. The numbers in parentheses show ranks of sectors according to their respective linkages.

choice of sectors for evolving any regional development strategy becomes very difficult particularly when the planners have multiple objectives.

The backward linkage patterns based on output, employment, income and wage income multiplier matrices are quite dissimilar to those of Gujarat. For example, in the case of Haryana linkage patterns based on all counts correspond quite well and the backward linkage indices based on employment and induced employment indicate a high correlation. The patterns are quite different for Gujarat. The backward linkage indices based on output, employmentand income multiplier matrices indicate strong correspondence whereas the linkage indices based on output multiplier matrices show a weak correspondence with linkage indices computed on other counts.

The forward linkage patterns for Gujarat based on output, employment, income and wage income multiplier matrices and for Haryana based on income and wage income multiplier matrices show strong correspondence.
However, the linkages based on employment and induced employment indicate a negative correlation with the linkages based on wage income multiplier matrices.

\section{Sector Specific Linkage Patterns}

Gujarat shows high forward linkages computed on the basis of most counts except for the wage income multiplier matrix. Textile and machinery sectors indicate high backward linkages based on wage income and net value added multiplier matrices. The import leakages, by and large, do not change the high forward linkage potential of these sectors.

High backward linkage patterns are shown by the following sectors: agriculture and allied sector, mining, construction, textile, non-metallic mineral products, paper and paper products and salt. These sectors show greater than unit value for forward linkage indices without import leakages on more than two counts. However, this is not 


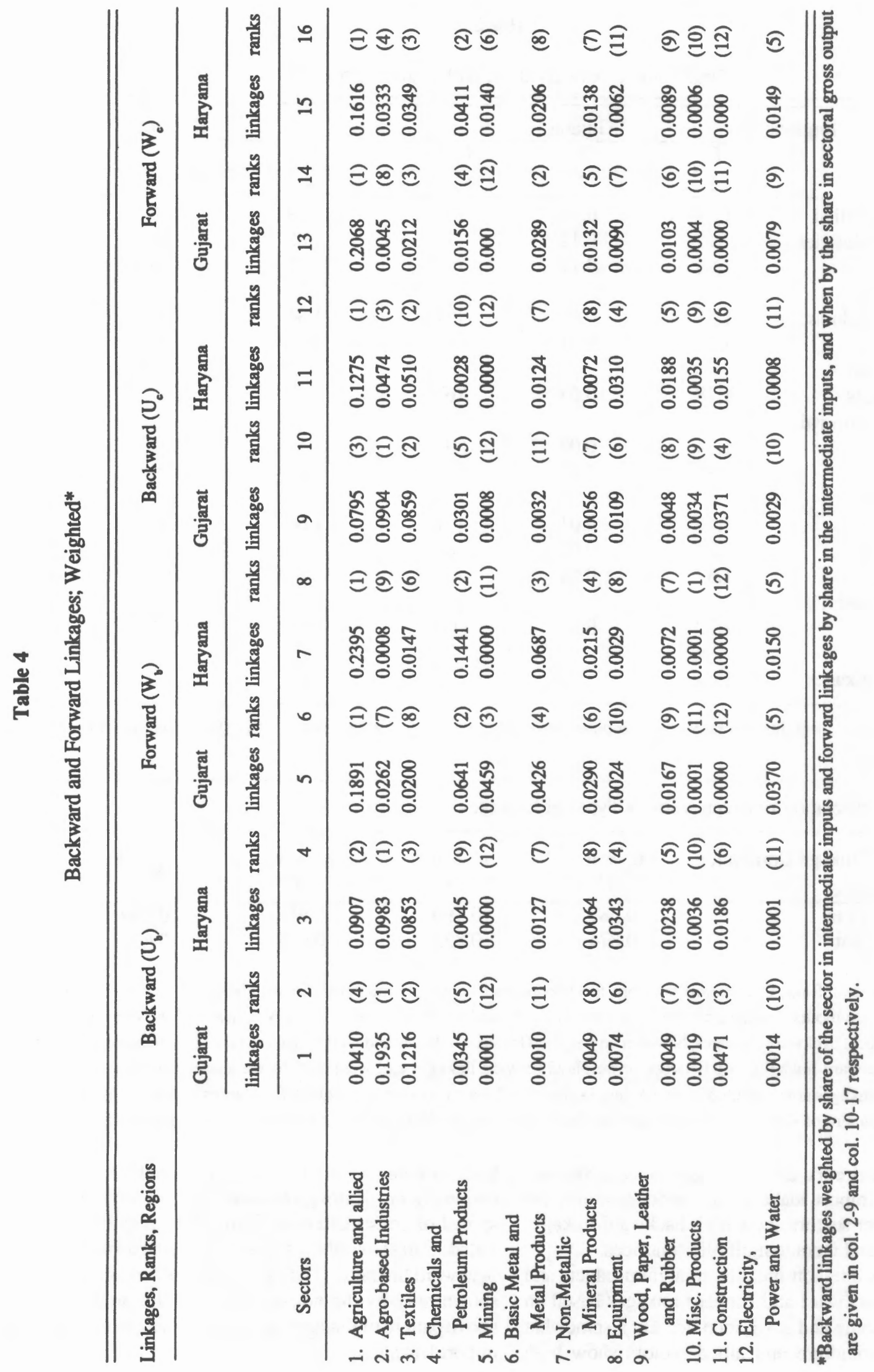


Table 5

Total Linkage Effects along with Ranks by Sectors

\begin{tabular}{|c|c|c|c|c|c|c|}
\hline \multirow[t]{3}{*}{ Regions } & \multicolumn{3}{|c|}{ Gujarat } & \multicolumn{3}{|c|}{ Haryana } \\
\hline & $\overline{T_{L j}}$ & W & Ranks & $\mathrm{T}_{\mathrm{Lj}}$ & W & Ranks \\
\hline & 1 & 2 & 3 & 4 & 5 & 6 \\
\hline 1. Agriculture \& allied & 1.24 & 0.39 & (9) & 1.29 & 0.56 & $(10)$ \\
\hline 2. Agro-based Industries & 2.17 & 0.12 & (1) & 1.85 & 0.07 & (1) \\
\hline 3. Textiles & 1.68 & 0.17 & (2) & 1.77 & 0.10 & (3) \\
\hline 4. Chemicals and & & & & & & \\
\hline Petroleum Products & 1.51 & 0.07 & (4) & 1.84 & 0.00 & (2) \\
\hline 5. Mining & 1.07 & 0.01 & (12) & 1.00 & 0.00 & (12) \\
\hline 6. Basic Metal and & & & & & & \\
\hline $\begin{array}{l}\text { Metal Products } \\
\text { 7. Non-metallic Mineral }\end{array}$ & 1.38 & 0.03 & (6) & 1.47 & 0.04 & (8) \\
\hline Products & 1.24 & 0.02 & (10) & 1.46 & 0.02 & (9) \\
\hline 8. Equipment & 1.34 & 0.05 & (7) & 1.55 & 0.09 & (6) \\
\hline $\begin{array}{l}\text { 9. Wood, Paper, } \\
\text { and Leather }\end{array}$ & 1.46 & 0.01 & (5) & 1.60 & 0.05 & (4) \\
\hline 10. Misc. Products & 1.27 & 0.02 & (8) & 1.49 & 0.01 & (7) \\
\hline 11. Construction & 1.57 & 0.08 & (3) & 1.57 & 0.04 & (5) \\
\hline $\begin{array}{l}\text { 12. Electricity, Power, } \\
\text { and Water }\end{array}$ & 1.20 & 0.02 & (11) & 1.06 & 0.01 & (11) \\
\hline Average Total Linkages & 1.43 & & & 1.50 & & \\
\hline
\end{tabular}

Source: Total linkages, weights and ranks are computed from aggregated input-output table (12X12) of Gujarat and the Haryana economies

Coefficients of Correlation Between Various Types of Linkages

\begin{tabular}{lcccc}
\hline Linkage Correlation & $\mathrm{u}_{\mathrm{A}} \& \mathrm{u}_{\mathrm{B}}$ & $\mathrm{u}_{\mathrm{A}} \& \mathrm{u}_{\mathrm{C}}$ & $\mathrm{w}_{\mathrm{A}} \& \mathrm{w}_{\mathrm{B}}$ & $\mathrm{w}_{\mathrm{A}} \& \mathrm{w}_{\mathrm{c}}$ \\
\cline { 2 - 5 } Regions & 1 & 2 & 3 & 4 \\
\hline Haryana & 0.587 & 0.490 & 0.916 & 0.740 \\
Gujarat & 0.874 & 0.825 & 0.678 & 0.439
\end{tabular}

Source: Coefficient of Rank Correlation between the unweighted backward linkages and weighted (by share of the sector in intermediate inputs) backward linkage, between unweighted backward linkages and weighted (by the share in fractional gross output) backward linkages, between unweighted forward linkages and weighted (by share of the sector in intermediate inputs) forward linkages, and between unweighted forward linkages and weighted (by the share in sectoral gross output) forward linkages are computed from the Haryana and the Gujarat economies and given in columns 1,2,3, and 4, respectively. The coefficient of Rank-Correlation between the Gujarat and the Haryana economies is very high and positive (0.94).

true for wood and cork and the miscellaneous product sectors. When import leakages are accounted for, the electric and power sectors show high backward linkages based on output and income multiplier matrices.

The sectors like non-metallic mineral products and salt show high backward and forward linkages based on employment, income and wage income. On a somewhat similar basis, agriculture and allied sectors show high backward and forward linkages as a result of income and employment. Among these sectors, the forward linkage spread of construction and agriculture is highly concentrated. Salt shows this pattern for both the forward and the backward linkages. The even spread of linkage patterns is shown only by the non-metallic mineral products. The above pattern of linkages remains the same with or without import leakages. 
For Haryana, sectors are divided into farm and nonfarm sectors. The farm sectors (1 to 10) show high forward and backward linkages on the basis of wage income and income inducement. Some of the farm sectors also show a high output inducement. These patterns are true even if the import leakages are accounted for. For example, wheat, sugarcane, agriculture and animal husbandry sectors show high forward linkage inducements on the basis of output, income and wage income. When import leakages are considered, some agro-based activities in Haryana show high backward linkages on the same account.

As far as regional employment opportunities are concerned, Haryana does not have many activities that havehighemployment, wage incomeand income inducement. The forward linkage pattern of electricity alone shows high potential for such inducements. If we analyze a linkage pattern "withand without" import leakages then the forward linkages of basic metal industries show high employment and output inducements.

In sum, employment and income inducements for Haryana do not belong to the same group of sectors. Farm sectors generally indicate high backward and forward linkages on account of income and wage income. Food processing, metal and machinery sectors in general indicate high employment linkageseffect and the output inducement effects appear common to both sets of sectors, farm and non-farm.

In Haryana, the new farm technology has led to quite favorable employment and income inducement effects. However, any further drive of mechanization may have adverse effects on both direct and total employment generation.

On the basis of linkage analysis, one can conclude that regional economies have quite marked differences in their inducement effects of employment, output, income and wage income. The more specific conclusion for Gujarat should concern regional planners. It is surprising that Gujarat, being one of the industrialized states, the highest income and employment inducements are generated by land-based and mineral-based activities.

For Gujarat, linkage analysis suggests that any regional development strategy based on output inducement effects alone, as hypothesized by Hirschman, can make other objectives of economic development such as employment and income generation even worse.

On the other hand, the "key sector strategy" for Haryanamaynotresultingenerating incomeandemployment simultaneously. In fact it is observed that the linkage spread of most of the high linkage sectors is accentuated. The income and employment inducements can be broken up into two well-defined sets of activities: the income inducements primarily coming from farm sectors and the employment inducements mainly belonging to food pro- cessing, metal and machinery sectors. Therefore, in order to generate income and employment, the prevailing pattern of industrialization in Haryana may have to be reversed. This conclusion for Haryana is further confirmed by Bhalla (1971).

The linkage indices computed for aggregate I-O tables of Gujarat and Haryana, using Yutopoulos and Nugent's technique, by and large, do not distort the pattern of linkages. The Haryana economy has higher indices for most sectors with the exception of agro-based industries and electricity, power and water sectors. The available linkage indices for Haryana, as a whole, is marginally higher than the Gujarat economy. The sectoral coefficient of rank correlation among the two regional economies, in general, indicate quite higher values. One can conclude from the linkage analysis that the Haryana economy is more developed than the Gujarat. This finding cannot be supported because the conditional indices for levels of economic development and structural composition indicate otherwise. It is quite surprising that an industrialized economy of Gujarat showed higher linkage indices in agrobased activities and an agriculturally developed economy of Haryana shows higher linkage indices in chemicals and petroleum products.

Thus, in the light of both the empirical studies done earlier as well as the observed linkage patterns in the regional economies, it is quite clear that the comparison of regional differences in the structure of production, on the basis of linkages, do not carry us very far in analyzing regional economies. Most conclusions pertaining to a regional development strategy, based on the size and patterns of linkages clamor for theoretical validity and empirical substantiation.

The analysis of the final demand vector (household and government consumption, capital formation, and net exports), on the other hand, indicates marked differences in all of its components. The distinct structure of final demand explains the interregional structure of production. Household consumption was estimated from the National Sample Survey of consumption expenditure. The government consumption component of final demand was estimated on the basis of "informed judgment." This vector was generated by applying the proportions found in the input-output table for India to regional budget estimates of expenditure. The capital formation vector is purely arbitrary and the result of guesswork. The treatment of trade flows is entirely different for the two regions. In Gujarat, exports and imports are identified in the final demand vector. Non-competitive imports of intermediate products were placed in a row in the input-output table. Haryana's table also identifies non-competitive imports in a row and estimates a residual final demand vector which has been interpreted as a net export or import vector. There are two 
Table 6

Sectoral Composition of Final Demand

\begin{tabular}{|c|c|c|c|c|c|c|c|c|}
\hline \multirow[b]{2}{*}{$\overline{\text { Regions }}$} & \multicolumn{2}{|c|}{$\begin{array}{l}\text { Government } \\
\text { Consumption }\end{array}$} & \multicolumn{2}{|c|}{$\begin{array}{l}\text { Household } \\
\text { Consumption }\end{array}$} & \multicolumn{2}{|c|}{$\begin{array}{l}\text { Total Final } \\
\text { Demand }\end{array}$} & \multicolumn{2}{|c|}{$\begin{array}{l}\text { Total Minus } \\
\text { Residuals }\end{array}$} \\
\hline & Gujarat & Haryana & Gujarat & Haryana & Gujarat & Haryana & Gujarat & Haryana \\
\hline Sectors & 1 & 2 & 3 & 4 & 5 & 6 & 7 & 8 \\
\hline 1. Agriculture and Allied & 0.66 & 3.64 & 55.05 & 73.94 & 51.15 & 80.31 & 40.71 & 57.89 \\
\hline 2. Agro-based Industries & 0.32 & 0.00 & 26.76 & 13.63 & 23.22 & 14.04 & 19.83 & 10.93 \\
\hline 3. Textiles & 4.55 & 4.34 & 7.28 & 5.80 & -15.57 & -14.34 & 6.26 & 5.74 \\
\hline 4. Chemicals and & & & & & & & & \\
\hline Petroleum Products & 12.87 & 1.42 & 4.36 & 3.23 & 1.50 & 18.22 & 3.63 & 2.56 \\
\hline 5. Mining & 0.00 & 16.41 & 0.0 & 0.77 & 0.27 & 0.77 & 0.00 & 0.32 \\
\hline 6. Basic Metal and & & & & & & & & \\
\hline $\begin{array}{l}\text { Metal Products } \\
\text { 7. Non-metallic Mineral }\end{array}$ & 2.54 & 0.00 & 0.55 & 0.09 & 3.88 & -2.88 & 2.21 & 0.27 \\
\hline Products & 1.03 & 5.87 & 0.85 & 0.04 & 0.59 & -5.97 & 0.66 & 0.15 \\
\hline 8. Equipment & 52.40 & 61.98 & 1.02 & 0.06 & 11.07 & -4.05 & 7.84 & 8.53 \\
\hline $\begin{array}{l}\text { 9. Wood, Paper, Leather } \\
\text { and Rubber }\end{array}$ & 16.90 & 5.02 & 0.83 & 2.63 & 2.00 & -3.06 & 1.18 & 3.57 \\
\hline 10. Miscellaneous Products & 2.66 & 1.32 & 2.70 & 0.23 & 1.57 & -4.80 & 2.08 & 0.21 \\
\hline 11. Construction & 0.00 & 0.00 & 0.0 & 0.00 & 19.10 & 20.06 & 14.92 & 9.56 \\
\hline $\begin{array}{l}\text { 12. Electricity, Power } \\
\text { and Water }\end{array}$ & 6.07 & 0.00 & 0.60 & 0.35 & 1.22 & .1 .70 & 0.68 & 0.27 \\
\hline
\end{tabular}

Source: Calculated from aggregate input-output table of Gujarat and Haryana (12X12). Figures for various components of final demand are given in percentage terms.

important factors: levels of income and differences in rural and urban compositions, which explain the differences in the structure of household consumption. After an adjustment is made for the residuals, it is significant to know that the differences in the final demand vectors are not as great as they are in the unadjusted structure of household consumption shown in Columns 4 and 5 of Table 6.

The sectoral composition of residuals or net exports enables us to identify the net exporting and importing sectors. Table 7 shows that the main exporting sectors of the Gujarat economy are textiles and petroleum and net importing sectors are basic metals and equipment. The relative size of the exporting sectors is ten fold of the net imports of the importing sectors. This indicates that the textile and petroleum sectors are far more important for the Gujarat economy than the purely regional sectors. A highly diversified economic structure has been revealed by the Haryana economy because its exports are distributed across all sectors with the exception of mining and petroleum and construction, which are natural resources specific and nontradable activity sectors, respectively. The size of the net exports for Haryana's economy is marginally larger than for Gujarat. However, in relation to its output, Haryana exports the same quantity but with half the gross output of Gujarat. The same conclusions are revealed by the fact that there is only one net importing sector i.e., chemicals and petroleum, and by the size of net exports, which is thirteen fold of the size of net imports.

One can also analyze the size of net exports and imports by comparing them with production in each sector. Once again, Table 7 gives better insight into the regional structure of production and interregional relationships.

The proportion of net exports to gross output for each sector for Haryana's economy, in general, is higher than for Gujarat. On the other hand, the net exporting and importing sectors for Gujarat's economy are more in accordance with the endowment of natural resources. However, the industrialization patterns for Haryana's economy are more responsive to the structure of final demand and relative cost advantages, which may be the result of government's forward looking development policies.

\section{Section V}

On the basis of the above discussion, we can conclude that the "leading sectors strategy" or study of struc- 
Table 7

\begin{tabular}{|c|c|c|c|c|c|c|c|c|}
\hline \multirow[b]{4}{*}{ Sectors } & \multirow{2}{*}{\multicolumn{2}{|c|}{$\begin{array}{l}\text { Sectoral Composition of } \\
\text { Residuals or Net Exports }\end{array}$}} & \multicolumn{4}{|c|}{$\begin{array}{l}\text { Sectoral Share of Net } \\
\text { Exports and Net Imports }\end{array}$} & \multicolumn{2}{|c|}{$\begin{array}{l}\text { Proportion of } \\
\text { Net Exports } \\
\text { to Gross Output } \\
\text { for Each Sector }\end{array}$} \\
\hline & & & \multicolumn{2}{|c|}{ Gujarat } & \multicolumn{2}{|c|}{ Haryana } & \multirow[b]{2}{*}{ Gujarat } & \\
\hline & Gujarat & Haryana & $\begin{array}{c}\text { Net } \\
\text { Exports }\end{array}$ & $\begin{array}{c}\text { Net } \\
\text { Imports }\end{array}$ & $\begin{array}{c}\text { Net } \\
\text { Exports }\end{array}$ & $\begin{array}{c}\text { Net } \\
\text { Imports }\end{array}$ & & Haryana \\
\hline & 1 & 2 & 3 & 4 & 5 & 6 & 7 & 8 \\
\hline 1. Agriculture and Allied & 3.58 & 41.73 & 3.20 & 0.00 & 38.45 & 0.00 & 1.11 & $\overline{18.40}$ \\
\hline 2. Agro-based Industries & 7.78 & 8.72 & 6.99 & 0.00 & 8.04 & 0.00 & 7.92 & 29.72 \\
\hline 3. Textiles & 83.95 & 19.97 & 75.41 & 0.00 & 18.40 & 0.00 & 59.59 & 44.51 \\
\hline $\begin{array}{l}\text { 4. Chemicals and } \\
\text { Petroleum Products }\end{array}$ & 11.24 & -8.59 & 10.08 & 0.00 & 0.00 & 100.00 & 18.35 & -395.77 \\
\hline $\begin{array}{l}\text { 5. Mining } \\
\text { 6. Basic Metal and }\end{array}$ & -0.97 & 0.00 & 0.00 & 8.56 & 0.00 & 0.00 & -8.77 & 0.00 \\
\hline $\begin{array}{l}\text { Metal Products } \\
\text { 7. Non-metallic Mineral }\end{array}$ & -3.77 & 2.51 & 0.00 & 33.26 & 2.31 & 0.00 & -16.38 & 16.18 \\
\hline Products & 0.92 & 4.48 & 0.85 & 0.00 & 4.15 & 0.00 & 6.10 & 43.64 \\
\hline 8. Equipment & -3.06 & 17.70 & 0.00 & 32.01 & 16.07 & 0.00 & -9.77 & 48.82 \\
\hline $\begin{array}{l}\text { 9. Wood, Paper, Leather } \\
\text { and Rubber }\end{array}$ & -1.70 & 8.07 & 0.00 & 15.04 & 7.62 & 0.00 & 15.64 & 43.66 \\
\hline 10. Miscellaneous Products & 3.89 & 3.75 & 3.49 & 0.00 & 3.46 & 0.00 & 28.00 & 88.07 \\
\hline 11. Construction & 0.00 & 0.00 & 0.00 & 0.00 & 0.00 & 0.00 & & \\
\hline $\begin{array}{l}\text { 12. Electricity, Power } \\
\text { and Water }\end{array}$ & -1.26 & 1.66 & 0.0 & 11.13 & 1.52 & 0.00 & -9.05 & 31.29 \\
\hline Total & 100.00 & 100.00 & 100.00 & 100.00 & 100.00 & 100.00 & 12.30 & 4.40 \\
\hline $\begin{array}{l}\text { Values for net exports and } n \\
\text { given in million rupees crore }\end{array}$ & ports & & 35.28 & 3.59 & 35.73 & 2.81 & & \\
\hline
\end{tabular}

Source: Net exports or net imports are referred to as interregional flows in aggregated input-output table (12X12) of the Gujarat and the Haryana economies. A negative figure in columns shows net imports.

tural changes in the process of economic development based on the linkage patterns may not be appropriate for the formulation of a regional development strategy. The spread of linkages of most of the high linkage sectors in Haryana is quite concentrated. Hirschman's unbalanced growth hypothesis that high priority be given to the sectors which show high linkages and low priority to others does not find much support on the basis of the data set used for this study. Rather, the prevailing patterns of industrialization may have to be reversed as noted earlier. It is also quite surprising that Gujarat, despite being one of the industrialized regions of India, the land and mineral based sectors are the one which generate the highest employment and income inducement effects.

We have also attempted a schematic categorization of different sectors on the basis of natural resource potential, import substitution, exports and high value for linkage indices and value added sectors criteria. The analysis of Table 8 reveals that the high linkage and the value added criteria are not quite relevant for the development of the production sectors of these regions.

Finally, the alternative hypothesis based on natural resource endowment and relative cost advantages or disadvantages for the exporting and importing sectors seems more appropriate for regional analysis in developing economies. The availability of essential resources and demand considerations based on cost advantages are far more important for comparison of regional structures of production and for evolving any suitable strategy of regional development. Therefore, economic policies must particularly be directed at overcoming the locational disadvantages of the exporting and importing sectors which are 
Table 8

Classification of Sectors According to Different Criteria

\begin{tabular}{|c|c|c|c|c|}
\hline $\begin{array}{l}\text { Classification } \\
\text { Criteria } \\
\text { Regions }\end{array}$ & $\begin{array}{l}\text { Natural } \\
\text { Resource } \\
\text { Potential }\end{array}$ & $\begin{array}{l}\text { Export Demand } \\
\text { or revealed } \\
\text { comparative advantage } \\
\text { sectors }\end{array}$ & $\begin{array}{l}\text { Import } \\
\text { Substitution } \\
\text { Sectors }\end{array}$ & $\begin{array}{l}\text { High Linkage sectors } \\
\text { (above state average) }\end{array}$ \\
\hline 1. Gujarat & $\begin{array}{c}\text { Agro-based } \\
\text { Textiles; Chemicals } \\
\text { and Petroleum } \\
\text { Products }\end{array}$ & $\begin{array}{l}\text { Agriculture; Agro-based } \\
\text { Textiles; Chemicals } \\
\text { \& Petroleum Products; } \\
\text { Non-metallic Minerals; } \\
\text { Misc. Products }\end{array}$ & $\begin{array}{c}\text { Mining; Basic } \\
\text { Metal; Equipment; } \\
\text { Wood, Paper, Leather } \\
\text { and Rubber; Electricity }\end{array}$ & $\begin{array}{l}\text { Agro-based Textiles; } \\
\text { Chemical \& Petroleum } \\
\text { Products; Wood, Paper, } \\
\text { Leather and Rubber; } \\
\text { Construction }\end{array}$ \\
\hline 2. Haryana & $\begin{array}{l}\text { Agro-based } \\
\text { Textiles }\end{array}$ & $\begin{array}{l}\text { Agriculture; Agro-based } \\
\text { Textiles; Basic Metal } \\
\text { and Metal Products; } \\
\text { Non-metallic Minerals; } \\
\text { Equipment; Wood, Paper, } \\
\text { Leather and Rubber; } \\
\text { Misc. Products; } \\
\text { Electricity }\end{array}$ & $\begin{array}{c}\text { Chemical and Petroleum } \\
\text { Products }\end{array}$ & $\begin{array}{l}\text { Agro-based Textiles; } \\
\text { Chemical \& Petroleum } \\
\text { Products; Wood, Paper } \\
\text { Leather, Rubber; } \\
\text { Construction }\end{array}$ \\
\hline
\end{tabular}

Source: The I-O table (16X16) for the year 1969-70, by S.P. Kashyap for Gujarat summarized in Anvesak, Vol. VI, No. 2, December 1976. The I-O table (32X32) for the year 1969-70 prepared by G.S. Bhalla for Haryana, 1974. The Sectoral classification is based on the disaggregate I-O tables for two regions.

oriented towards natural resources. This also points to the need for focusing research efforts towards the explicit identification of regional trade flows, natural resource position, change in technology and relative costs of factor inputs and changes in demand outside the regions, etc., for evolving any strategy for regional development.

It should be noted, however, there are limitations of our analysis because of the inadequate nature of the data base. In all faimess, we must admit that the linkage indices calculated from our information base are likely to be sensitive to the level of aggregation, price variations, technological and structural changes. Bhardwaj (1966) noted this limitation of linkage analysis for comparing the structure of production and identifying the "key" sectors. The input coefficients of some sectors have been taken directly from the "technical note" of five- year plans which introduces errors into the scheme of sectoral classification. Computations for the sectoral value added ignores regional variations that may also cause some errors.

There are other limitations associated with generating regional trade flows under the restrictive assumptions of fixed technology and the independent identification of a technology matrix. The difficulty, however, with the first commonly-used approach is that the underlying assumptions of a fixed technology matrix appear unreal by itself. A fixed interregional trading pattern would result in a fixed production pattern making the problem of locational choice an irrelevant one. Whereas in the second approach, the difficulty in the assumptions that the regional technology as well as the regional consumption and investment vectors are given on a firm and factual basis.

\section{References}

Bhalla, G.S., "Structure of the Haryana Economy: Inter-Industry Flows and Pattems of Final Demand, 1969-70," Indian Council of Social Science Research sponsored Project, (mimeograph), 1975.

"Sectoral Income Multipliers in Punjab and India," Anvesak, Vol. I, No. 2, December 1971, pp. 210-229.

Bhardwaj, R. Krishana, "A Note on Structural Interdependence and the Concept of key sector," Kyklos, Vol. 19, 1966, pp. 315-319.

Boucher, M., "Some Further Results on the Linkage Hypothesis, Quarterly Journal of Economics, Vol. XC, No. 2, May 1976, pp. 313-318. 
Bourque, P.J. and E. E. Weeks. Detailed Input-Output Tables for Washington State, 1963, Pullman, Washington: Washington Agricultural Experiment Station, 1969.

Chapman, J. H. and K. L. Shellhammer. Structure of West Virginia Economy, 1965, Morgantown, W.Va.: Research Institute, 1967.

Chenery, H. B., and T. Watanabe, "International Comparisons of the Structure of Production," Econometrica, Vol. 26, No. 4, October 1958, pp. 487-507.

Dutta-Chaudhari, M. K., "Inter-Industry Planning Models for a Multi-regional Economy," in Blitzer, C. R., P. B. Clark; and L. Taylor, Economy Wide Models and Development Oxford: Oxford University Press, 1975.

Emerson, M. J., “An Inter-industry Comparison of Regional and National Economic Structure," Papers of the Regional Science Association, Vol. 26, 1971, pp. 165-177.

et. al. The Inter-industry Structure of the Kansas Economy, Topeka: State of Kansas, 1969.

Ghosh, P. P., "Intersectoral Transactions in Producers' Prices in the Bihar Economy, 1969-70," mimeograph, A. N. Sinha Institute of Social Studies, Patna, 1974.

Grubb, H. W., "The Structure of the Texas Economy," Vol. 2, Austin, Texas: Office of the Governor, Office of Information Services, 1973.

Helmstadter, E., "The Hierarchical Structure of International Transactions," in International Comparison of Inter-industry Data, New York: United Nations, 1969.

Jones, Leory P., "The Measurement of Hirschmanian Linkages," Quarterly Joumal of Economics, Vol. XC, No. 2, May 1976, pp. 323-33

Kashyap, S. P. and Y. K. Alagh, "Structure of Gujarat's Economy: Inter-Industry Flows at Producers' Prices, 1964 65," Sardar Patel Institute of Economic and Social Research, Ahmedabad, (mimeograph), 1971.

Koti, R. K. and K. V. Santhanam, "An Input-Output Table for Maharashtra at Purchasers' Prices," mimeograph, Tata Institute of Consultancy Services, Bombay, 1963.

Laumas, S. Prem., "The Weighting Problem in Testing the Linkage Hypothesis," Quarterly Journal of Economics, Vol. XC, No. 2, May, 1976, pp. 308-312.

Leontief, W., "An Altemative to Aggregation in Input-Output Analysis and Rational Accounts,"The Review of Economics and Statistics, Vol. 49, No. 3, August 1967, pp. 412-419.

Long, B.Neal, Jr., "An Input-Output Comparison of the Economic Structure of the U.S. and the U.S.S.R.," The Review of Economics and Statistics, Vol. LII, No. 4, November 1970, pp. 434-441.
Mathur, P. N., et. al., "Input-output Flow Table (32 x 33) (At Purchasers' Prices)", Artha Viinana, Vol. 11, No. 2, June 1969, pp. 181-199.

Mehta, B. C., "Structure of Rajasthan Economy, 1970-71," (mimeograph), 1977.

Mennes, L. B. M., Tinbergen, J. and Waardenburge, J. G., The Element of Space in Development Planning, New York: North Holland, 1969.

Miernyk, W. H., et. al., Simulating Regional Economic Development Lexington Mass: Lexington Book, 1970.

Morawski, W., "Balance of Inter-regional Commodity Flows in Poland: A Value Approach," in Blunden, J. Brook, C., Edge, G. and Hay, A., Regional Analysis and Development, Open University, 1973.

Rasmussen, P. N., Studies in Intersectoral Relations, North-Holland, Publishing Company, Amsterdam, 1956.

Ragnekar, G., "Structure of Punjab Economy, 1965-66," (mimeograph), 1969.

Riedel, J., “A Balance-Growth Version of the Linkage Hypothesis: A Comment," Quarterly Joumal of Economics, Vol.XC, No. 2, May 1976, pp. 319-322.

Rudra, A., Indian Plan Models, Allied Publishers Pvt. Ltd., 1975.

Saluja, M. R., "Structure of Indian Economy: Inter-Industry Flows and Pattem of Final Demands, 1964-65," Sankhya. Series B, 1968, pp. 97-122.

Schultz, Siegfried, "Approaches to Identifying Key Sectors Empirically by Means of Input-Output Analysis," ooumal of Development Studies, Vol. 14, No. 1, October, 1977, pp. 77 96.

Simpson, D. and Tsukui, J., "The Fundamental Structure of InputOutput Tables: An International Comparison,"The Review of Economics and Statistics, Vol.47, November, 1965, pp.434446.

United Nations, Department of Economic and Social Affairs, Poverty, Unemployment and Development Policy: A Case Study of Selected Issues with Reference to Kerla New York, 1975, p. 1.

Vyas, V. S., "Structural Change in Agriculture and the Small Farm Sector," Presidential Address, Seventh Gujarat Economic Conference, Bulsar, November, 1975.

Yutopoulos, A. P. and Nugent, B. Jeffrey, "A Balance-Growth Version of the Linkage Hypothesis: A Test," Quarterly Journal of Economics, Vol. LXXXVII, No. 2, May 1973, pp. 157-171.

"In Defense of a Test of the Linkage Hypothesis," Journal of Economics, Vol. XC, No. 2, May 1976, pp. 334 343. 